\title{
Optimizing Traffic Operation in Designing Specific Upgrades
}

\author{
Ebrahim Sangsefidi, ${ }^{1}$ Mohammadjafar Rashidbenam, ${ }^{1}$ Shahab Kabiri, \\ Hossein Amid, ${ }^{3}$ and Maryam Sangsefidi ${ }^{4}$
}

${ }^{1}$ SES, Consulting Engineers, Tehran, Iran

${ }^{2}$ Civil Engineering Department, K.N.Toosi University of Technology, Tehran, Iran

${ }^{3}$ Civil Engineering Department, Azad University, Boushehr Branch, Boushehr, Iran

${ }^{4}$ Engineering Department, Ferdowsi University of Mashhad, Mashhad, Iran

Correspondence should be addressed to Ebrahim Sangsefidi; ebrahim.sangsefidi@gmail.com

Received 1 July 2014; Accepted 29 December 2014

Academic Editor: Yingfeng (Eric) Li

Copyright (C) 2015 Ebrahim Sangsefidi et al. This is an open access article distributed under the Creative Commons Attribution License, which permits unrestricted use, distribution, and reproduction in any medium, provided the original work is properly cited.

\begin{abstract}
Transport forms one of the primary needs in all categories of the population in modern society; it is of paramount concern for traffic engineers, transport planners, and policy makers to understand and evaluate the quality of service being provided by the transport facilities designed by them. This paper presents an investigation in profile geometric design and traffic flow operation on two-lane two-way highways and provides analyses that will help in a better understanding of traffic operation on these facilities to select the optimum profile configuration. The effects of influencing parameters consisting of grade, length of grade, traffic composition, and traffic volume are evaluated and finally a systematic procedure to evaluate flow rate under the base condition is presented. Finally, based on these achievements an algorithm is introduced to select optimum Finished Ground of profile view. Results show that the percentage of heavy vehicles has a contributing effect on traffic operation so that the optimum profile configuration is incredibly affected by this factor. Source data have been obtained from Highway Capacity Manual (HCM) as a pioneer document in respect of quantifying the concept of capacity for a transport facility.
\end{abstract}

\section{Introduction}

Two-way two-lane highways (TWTLHs) are a key element in the highway systems of most states and counties [1-3]. They are located in many different geographical areas and serve a wide variety of traffic functions [3]. The most widely accepted two-lane highway capacity and quality-of-service analysis procedures are those presented in the HCM published by the Transportation Research Board [1]. This manual defines TWTLHs as undivided roadways with two lanes, one for use by traffic in each direction [3-6], where the opposite lane can be used for passing other vehicles going in the same direction $[5,6]$.

The analysis of traffic performance for TWTLHs is one of the most important aspects to consider while undertaking the planning, design, and operation of these facilities $[4,5,7$, 8]. It is a major input to important decisions on public fund investments that are made at different stages of the highway life $[4,7,8]$.
The capacity conditions of this special infrastructure of transportation are difficult to be observed in the field, since very few two-lane roads operate at or near capacity and most of the times road improvement or upgrading is done prior to operations at capacity conditions $[1,5]$. The latest version of HCM underlines that the capacity can only be determined separately for each direction and that total roadway capacity is to be determined by weighted average of the one-direction results [3]. Therefore, in this manual, the capacity under ideal condition is given as $1700 \mathrm{veh} / \mathrm{h}$ per one direction and a limit of $3200 \mathrm{veh} / \mathrm{h}$ for the total of two directions as previously mentioned in the $2000 \mathrm{HCM}$ version $[3,5]$. Previous studies result in a variety of findings concerning the effect of different parameters on TWTLH capacity. In this regard, [9] investigated the capacity of TWTLHs using simulation method and found that the capacity under ideal conditions as defined previously varies with the average freeflow speed [5]. Further discussion on this topic is available in $[5,10,11]$. 
Traffic operation on TWTLHs differs from other facilities due to the unique relationship between traffic conditions in the two directions of travel $[3,4]$. For example, the capacity of two-lane roads is far less than the multilane facilities. The passenger car equivalent of trucks and buses is much greater for those facilities than the multilane facilities because of reduced opportunity for other automobiles to pass slower vehicles [12]. Also because passing capacity decreases as passing demand increases, two-lane highways exhibit a unique characteristic: operating quality often decreases precipitously as demand flow increases, and operation can become "unacceptable" at relatively low volume-to-capacity ratios $(V / C)$. For this reason, few two-lane highways ever operate at flow rates approaching capacity; in most cases, poor operating quality has led to improvements or reconstruction long before capacity demand is reached [3]. In simpler term, TWTLHs are known for their higher level of interaction between vehicles in the opposing directions of travel and therefore provide unique challenges to traffic analysts $[2,4]$. As traffic level increases, passing opportunities become more restricted and this interaction deteriorates.

From a traffic operations perspective, limited passing opportunities would result in higher impact of slow-moving vehicles on mobility and performance [2]. This impact generally intensifies with the increase in traffic level in the two directions of travel, the proportion of slower vehicles in the traffic stream, and the average speed differential between slower vehicles and the rest of the driver population $[4,13]$. Kim and Elefteriadou [9] showed that traffic composition strongly influences the capacity of two-lane road highways, since the increase in percentage of trucks particularly in the presence of horizontal curve, driveway, and upgrade results in significant capacity reduction. The study using the simulation software "TWOSIM" also shows that some geometric factors, namely, the grade of the upgrade segment, exhibit a considerable negative impact on the highway capacity $[5,9]$. The vehicles in the mix produce different impedance due to their varied static and dynamic characteristics $[14,15]$. Reference [12] considers the design characteristics of a facility as a main contributor to determine the performance of that facility in accommodating the vehicle traffic load placed upon it. Reference [16] studies the effect of variation of traffic volume, road width, magnitude of upgrade, and its length on PCU values for various vehicle categories using simulation. Reference [17] observed that knowledge of traffic composition plays an important role in determining capacity.

The effect of geometric properties on the operating characteristics of TWTLHs has been the subject of a number of studies. Much of the earlier work in this area is reviewed by [18] and has been incorporated into the first two editions of the US HCM $(1950,1965)$ [19]. Using 1963 data, [20] found that grade, for all vehicle types, is the most significant factor for predicting free speeds and $[19,21]$, using similar data, found that, in general, an increase in grade, either upgrade or downgrade, decreases speeds. Geometric characteristics such as grades greater than 4 percent were also found to have relationships with the crash rate [15].

In general, there seems to be a lack of guidance, in any, in answering the following question about TWTLHs: If designer

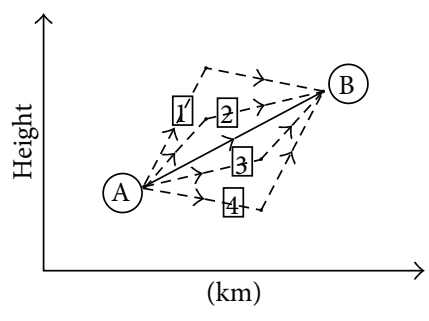

FIGURE 1: Different available options on selecting FG lines.

has the ability to choose different vertical alignment designs, which one would perform better from the standpoint of traffic operation? The answer to this question could be of a real concern in design of profile views on two-lane highways.

\section{Problem Statement}

Alignment design of a highway is usually considered from two different aspects which are strictly connected to each other: horizontal and vertical alignments. The horizontal alignment design generates the "plan view" while vertical alignment design generates the "profile view" of a particular highway. In general, geometric design of highways is a complex and exhausting process, while the designer deals with an extent of problems which are not solely related to geometric design, such as traffic operation. A common aim of transportation management and control projects on freeways is to increase productivity by reducing congestion [22]. Knowing the traffic operation benefits of a particular design would allow the selection of the most appropriate profile view. So the focus of this research is to demonstrate a methodology to find the effects of profile view variation on the expected traffic operation on TWTLHs and introduce a method to choose the optimum Finished Ground (FG) profile view from the standpoint of traffic operation.

Figure 1 illustrates a general depiction of the problem. As shown in this figure, in order to connect two points in profile view, named $\mathrm{A}$ and $\mathrm{B}$, there are several options and each one has its pros and cons. This study assumes that at least a couple of feasible variations on profile design exist in which the designer intends to select the best one from traffic view. This study approaches the problem from a different view which will be discussed later. It is noteworthy that the final decision must consider economic, geometric, and all other determinant aspects.

2.1. Assumptions. As how it is described in detail later, this study only considers TWTLHs segments in specific upgrades, on Class I and Class II (based on HCM 2010 classification). This study also assumes no recreational vehicles in traffic combination. It is definitely worth mentioning that, just as [3], heavy vehicles in this study are vehicles other than passenger cars (a category that includes small trucks and vans) that have more than four tires touching the pavement. Trucks and buses are the two groups of heavy vehicles addressed by the method in this research. 
2.2. Objectives. The objectives of this study are as follows:

(i) to understand two-lane highways phenomenon, in order to enhance the quality of service provided by this kind of highways in rural environment especially for specific grades,

(ii) to identify the effect of flow, profile geometric characteristics (grade and length of grade), and percent of heavy vehicle that significantly influence flow rate in mountainous areas on TWTLHs,

(iii) to establish a methodology that can be used in conjunction with HCM to determine optimum profile view in TWTLH facilities.

\section{Data Analysis}

3.1. Definitions. Because of the wide range of functions served by two-lane highways, HCM 2010 establishes three classes of two-lane highways of which Class I and Class II are evaluated in this study, as mentioned before. The main difference between these two classes is the motorist expectation of travel speed.

Performance analysis is typically done within the capacity analysis for various highway facilities. Performance is typically described using level of service (LOS), which is a letter scheme intended to describe traffic conditions for an existing or proposed facility operating under current or projected traffic demand [4]. The concept of LOS was formally introduced in the $1965 \mathrm{HCM}$ and was defined as follows: LOS is a qualitative measure of the effect of a number of factors, which include speed and travel time, traffic interruptions, freedom to maneuver, safety, driving comfort and convenience, and operating cost [3, 4, 23]. Based on [3], three measures of effectiveness are incorporated to determine automobile LOS: average travel speed (ATS), percent time spent following (PTSF), and percent of free-flow speed (PFFS). On Class I two-lane highways, speed and delay due to passing restrictions are both important to motorists. Therefore, on these highways, LOS is defined in terms of both ATS and PTSF. On Class II highways, travel speed is not a significant issue to drivers. Therefore, on these highways, LOS is defined in terms of PTSF only.

HCM 2010 [3] investigates the relationships among flow rate, ATS, and PTSF for an extended directional segment of two-lane highway under base conditions using two graphs (HCM 2010 ([3], Exhibit 15-2 a and b)). These graphs show that, on two-lane highways, service quality measures deteriorate with increasing flow rate, especially PTSF that begins to reduce at relatively low demand flows [3]. This represents the importance of reducing flow rate amount under HCM base conditions for TWTLs which are as follows: lane width greater than or equal to $3.6 \mathrm{~m}$, clear shoulders with width equal to or greater than $1.8 \mathrm{~m}$, absence of no-passing zones, traffic stream composed of only passenger cars, level terrain, and absence of obstruction through traffic [3]. Therefore, ignoring these relationships may lead to unjustified decisions regarding road construction, improvement, and evaluation of effectiveness of implemented traffic engineering measures, hence causing serious problems for transportation policy and economic considerations [5].

As shown in Table 1, [3] classifies grades, length of grades, and traffic flows for ATS estimation in 5, 8, and 9 groups, respectively. The same classification is used for PTSF estimation. These values are used as decision points in this study to evaluate the performance of specific upgrades.

Maximum grade in itself is not a complete design control. It is also appropriate to consider the length of particular grade in relation to desirable vehicle operation. The term "critical length of grade" is used by the American Association of State Highway and Transportation Officials (AASHTO) [24] to indicate the maximum length of designated upgrade on which a loaded truck can operate without an unreasonable reduction in speed. If desired freedom of operation is to be maintained on grades longer than critical length, design adjustments such as change in location to reduce grades or addition of extra lane should be considered [24].

The effect of trucks on capacity is primarily a function of the difference between the average speed of the trucks and the average running speed of the passenger cars on the highway. On individual grades, the effect of truck is more severe than their average effect over a longer section of highway. Thus, for a given volume of mixed traffic and a fixed roadway cross section, a higher degree of congestion is experienced on individual grades than for the average operation over longer sections that include downgrades as well as upgrades [24].

Heavy vehicles adversely affect traffic in two ways:

(i) they are larger than passenger cars and occupy more roadway space;

(ii) they have poorer operating capabilities than passenger cars, particularly with respect to acceleration, deceleration, and the ability to maintain speed on upgrades.

The second impact is more critical [3].

Reference [24] indicates that climbing lanes on two-lane highways are warranted when

(i) the directional flow rate on the upgrade exceeds $200 \mathrm{veh} / \mathrm{h}$,

(ii) the directional flow rate for trucks on the upgrade exceeds $20 \mathrm{veh} / \mathrm{h}$,

(iii) any of the following conditions apply:

(a) a speed reduction of $10 \mathrm{mi} / \mathrm{h}$ or more exists for a typical truck,

(b) LOS E or F exists on the upgrade without a climbing lane, or

(c) without a climbing lane, the LOS is two or more levels lower on the upgrade than on the approach segment to the grade.

In the latter case, decision is based on the LOS of the highway which is in direct relation with its flow rate. Thus, the flow rate of a highway in different situations is analyzed in this study to establish a comparison process between different vertical alignment designs. 
TABLE 1: Applied classifications of grade, length of grade, and traffic flow rate [3].

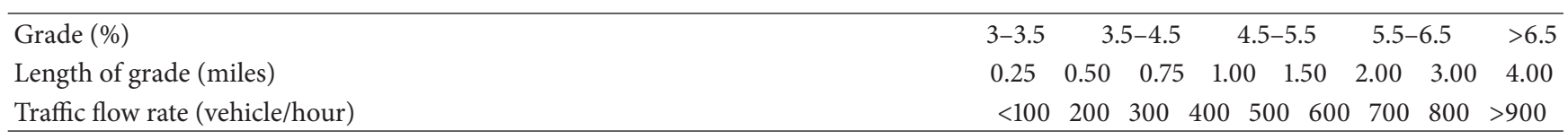

3.2. Development. The understanding of flow of many vehicles on a path is essential to the rational design of new facilities and to the modification of existing facilities to meet different traffic conditions [12].

It is believed that the increased number of vehicles does not give the authentic view of traffic operation. For this reason, traditionally, owing to the mixed traffic conditions, passenger cars have been taken as the basis of traffic flow measurement and hence the passenger car units (PCU) have been the widely adopted metric for assessing flow rate $[14,25]$. Many researchers have developed methods to estimate PCU for a vehicle type. The interesting point to note is that each of these studies has resulted in different PCU values for the same type of vehicle. There exists large variation in PCU values being adopted in different parts of the world. In this study, the heterogeneous demand volumes are converted to homogeneous equivalent flow rates under equivalent base conditions presented in [3] with

$$
v_{i, \mathrm{ATS} \text { or } \mathrm{PTSF}}=\frac{V_{i}}{\mathrm{PHF} \times f_{g, \mathrm{ATS} \text { or PTSF }} \times f_{\mathrm{HV}, \mathrm{ATS} \text { or PTSF }}}
$$

in which $v_{i \text {,ATS or PTSF }}$ is demand flow rate $i$ for ATS estimation ( $\mathrm{pcu} / \mathrm{h}$ ); $i$ is " $d$ " (analysis direction) or " $o$ " (opposing direction); $V_{i}$ is demand volume for direction $i$ (veh/h); $f_{g \text {,ATS or PTSF }}$ is grade adjustment factor; $f_{\mathrm{HV} \text {,ATS or PTSF }}$ is heavy vehicle adjustment factor; PHF is peak hour factor.

Note that, in (1), combination of factors PHF, $f_{g \text {,ATS or PTSF }}$, and $f_{\mathrm{HV} \text {,ATS or PTSF }}$ is used to convert the "demand volume" in terms of vehicle per hour to "demand flow rate" in terms of passenger cars per hour.

Considering that in the right side of (2) $V_{i}$ and PHF are constant for a given segment of highway (entitled " $C$ " here), the only varying terms would remain $f_{g}$ and $f_{\mathrm{HV}}$ which strictly depend on profile view configuration. A new parameter based on these varying terms, "Volume Conversion Coefficient, VCC", is introduced and defined as follows:

$$
\mathrm{VCC}=\frac{1}{f_{g, \mathrm{ATS} \text { or PTSF }} \times f_{\mathrm{HV}, \mathrm{ATS} \text { or PTSF }}} .
$$

And so

$$
v_{i, \mathrm{ATS} \text { or } \mathrm{PTSF}}=C \times \mathrm{VCC} \text {. }
$$

$f_{g}$ depends on the terrain through which the highway is passing and for specific upgrades is derived from a combination of grades, length of grade, and traffic volume. $f_{\mathrm{HV}}$ also is calculated based on the following equation [3]:

$$
f_{\mathrm{HV}}=\frac{1}{1+P_{T}\left(E_{T}-1\right)+P_{R}\left(E_{R}-1\right)},
$$

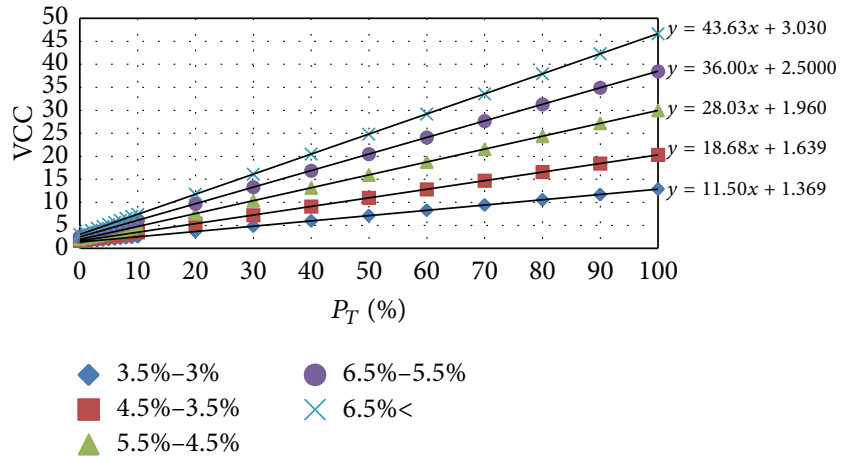

Figure 2: VCC $_{\text {ATS }}$ versus $P_{T}$ at $V=100 \mathrm{veh} / \mathrm{h}, L>4 \mathrm{mi}$, and various G.

where $P_{T}$ is proportion of trucks in the traffic stream (deci$\mathrm{mal}), P_{R}$ is proportion of RVs in the traffic stream (decimal), $E_{T}$ is passenger car equivalent for trucks, and $E_{R}$ is passenger car equivalent for RVs.

Having no recreational vehicles, (4) becomes

$$
f_{\mathrm{HV}}=\frac{1}{1+P_{T}\left(E_{T}-1\right)} .
$$

Similar to $f_{g}, E_{T}$ is also a function of grade, length of grade, and traffic volume composition [3].

It is noteworthy that varying percentages of trucks from zero to one hundred would result in a significant change of VCC and thus in final flow rate. Thus the percentage of heavy vehicles seems to be of interest in analyzing the performance of upgrades in addition to grade, length of grade, and traffic volume. It is also obvious that the point of interest is generally at the end of the grade, where heavy vehicles would have the maximum effect on operations [3].

It is interesting to note that a simple investigation reveals the linear relationship between VCC and the variation of heavy vehicles percent while grade $(G)$, length of grade $(L)$, and volume $(V)$ remain unchanged. The following equation shows this relationship:

$$
\mathrm{VCC}=a * P_{T}+b .
$$

Constants " $a$ " and " $b$ " depend on the $G, L$, and $V$ variation which will be discussed later. The combination of these three effective variables forms numerous data of which a few examples are shown in Figures 2 to 4 . For comparative purposes, each figure shows the linear relationship for the abovementioned parameters while only one of them changes in the predefined range determined in Table 1 while the others remain unchanged.

Figure 2 indicates the effect of $G$ changes on VCC. The magnitude of " $a$ " and " $b$ " (constants in (6)) increases with 


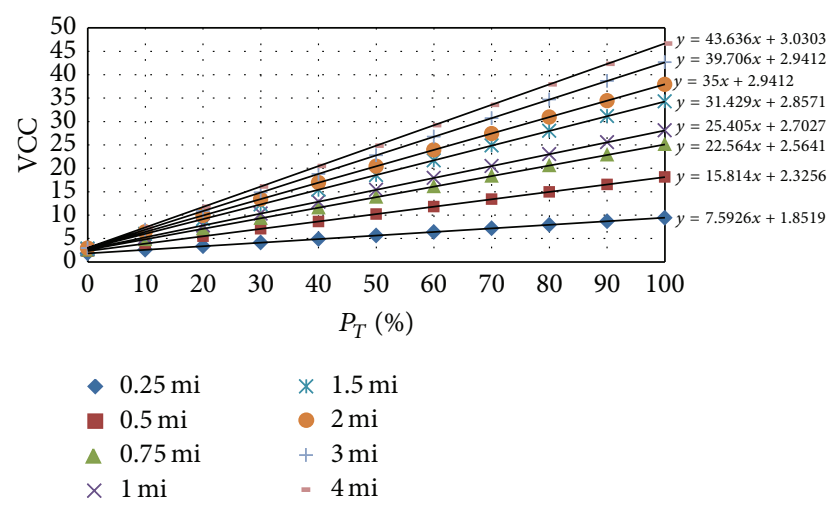

Figure 3: $\operatorname{VCC}_{\text {ATS }}$ versus $P_{T}$ at $V=100 \mathrm{veh} / \mathrm{h}$, various $L-G>6.5 \%$.

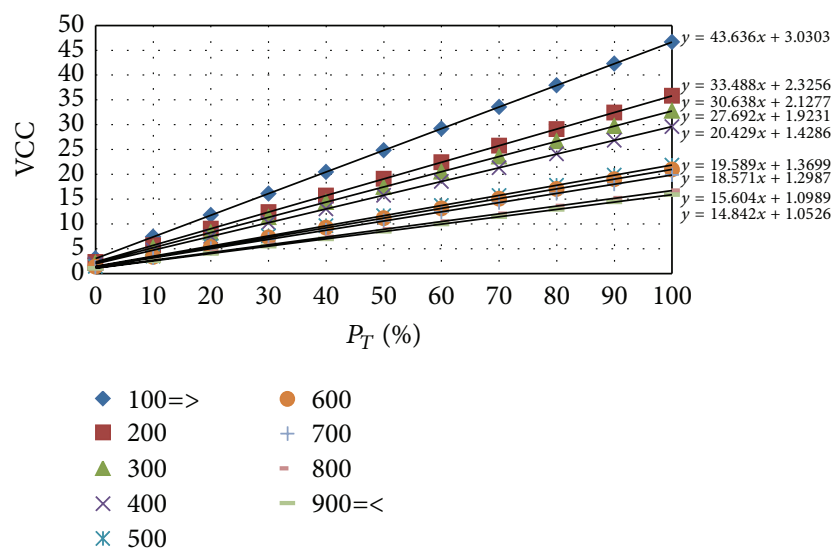

Figure 4: $\mathrm{VCC}_{\mathrm{ATS}}$ versus $P_{T}$ at various $V, L>4 \mathrm{mi}$, and grade > $6.5 \%$.

$G$ increment but changing rate of " $a$ " diminishes while " $b$ " changes in almost a constant rate. This indicates that reduction of $G$ has a significant effect on decreasing VCC and similarly on flow rate.

Comparable data for various $L$ are shown in Figure 3. As it is illustrated, the magnitude of " $a$ " and " $b$ " (constants in (6)) increases in an approximately decreasing rate with increasing the magnitude of $L$. Based on this analysis, a closer look at Figure 3 shows that reduction of $L$ has a significant effect on decreasing VCC and similarly on flow rate.

Figure 4 explores the effect of $V$ changes on VCC. The magnitude of " $a$ " and " $b$ " (constants in (6)) increases as $L$ decreases. This indicates that increasing of $V$ has a significant effect on decreasing VCC, but the impact on the flow rate cannot be judge using this figure. Generally, it seems that, based on (3) and Figure 4, decreasing of $V$ will decrease flow rate. This seems to be justified by the fact that lower flows are related to higher speeds, which render the existence of heavy vehicle a critical parameter. However, when flows are high, the traffic operates in lower speed and existence of heavy vehicle has lower effect on the traffic operation.

Above all, it is worth mentioning that the negative impact of upgrades on VCC adjustment factor increases as both the severity of the upgrade and its length increase. The impact, however, declines as demand flow rate increases. At higher

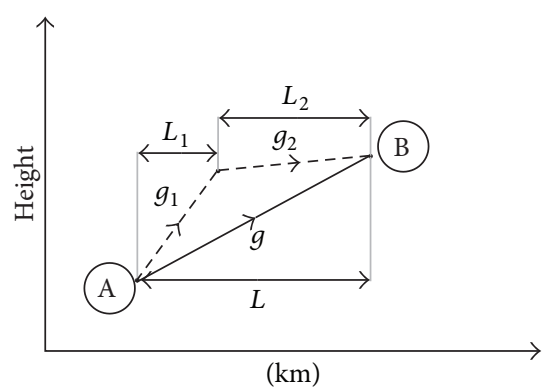

FIGURE 5: Sample study configuration.

demand flow rates, lower VCC would already result, and the additional impact of the upgrades is less severe. It is also apparent that charts with greater " $a$ " constant are more sensitive to the change of heavy vehicle volume and, as a result, it could be concluded that when a designer encounters steep and long grades or low traffic volumes, more rigorous attempt is needed to determine and predict heavy vehicles percentage. This fact renders the interaction importance of geometric features in the profile view and traffic operation condition. It is worth mentioning that the importance of this interaction seems to be justified mainly by the increased heavy vehicle percentage.

As discussed earlier, this research is about to determine the best configuration of profile view for specific traffic condition considering traffic operation aspect. A profile view consists of several tangent lines and, considering the main problem presented in Figure 1, there are several alternatives on how these tangents connected for a FG line.

\section{Sample Study and Results}

In this section, the result of the theory developed here is discussed to present a systematic method for FG optimization considering traffic operation. Figure 5 shows two alternatives to connect two points in profile view:

(1) a single tangent (the gradient and length are $g$ and $L$, resp.),

(2) two tangents (the gradients and lengths are $g_{1}, g_{2}, L_{1}$, and $L_{2}$, resp.). It is obvious that the composition of $\left(g_{1}, L_{1} ; g_{2}, L_{2}\right)$ has the same operation characteristics as $\left(g_{2}, L_{2} ; g_{1}, L_{1}\right)$.

If alternative (2) provides better traffic operation than alternative (1), other parameters such as economic consideration may highlight the selection of efficient profile from these two compositions.

There are a large number of combinations of which only a few examples are evaluated as follows:

(i) $g=3 \%$ and $L=3$ miles: the base condition between A and $\mathrm{B}$,

(ii) $V=100$ vehicles/hour for ATS, Table 2,

(iii) $V=900$ vehicles/hour for ATS, Table 4,

(iv) $V=100$ vehicles/hour for PTSF, Table 3,

(v) $V=900$ vehicles/hour for PTSF, Table 5. 
TABLE 2: VCC magnitude for ATS at $V=100$.

\begin{tabular}{|c|c|c|c|c|c|c|c|c|c|c|c|c|}
\hline \multirow{2}{*}{ Grade (\%) } & \multirow{2}{*}{$\begin{array}{l}\text { Grade length } \\
\text { (miles) }\end{array}$} & \multicolumn{11}{|c|}{ Percent of heavy vehicle } \\
\hline & & $0 \%$ & $10 \%$ & $20 \%$ & $30 \%$ & $40 \%$ & $50 \%$ & $60 \%$ & $70 \%$ & $80 \%$ & $90 \%$ & $100 \%$ \\
\hline$g=4$ & 3 & 1.64 & 3.34 & 5.05 & 6.75 & 8.46 & 10.16 & 11.87 & 13.57 & 15.28 & 16.98 & 18.69 \\
\hline \multicolumn{13}{|l|}{1} \\
\hline$g_{1}=8$ & 0.25 & 1.85 & 2.61 & 3.37 & 4.13 & 4.89 & 5.65 & 6.41 & 7.17 & 7.93 & 8.69 & 9.44 \\
\hline$g_{2}=3.63$ & 2.75 & 1.37 & 2.75 & 4.14 & 5.52 & 6.90 & 8.29 & 9.67 & 11.05 & 12.44 & 13.82 & 15.21 \\
\hline \multicolumn{13}{|l|}{2} \\
\hline$g_{1}=8$ & 0.5 & 2.33 & 3.91 & 5.49 & 7.07 & 8.65 & 10.23 & 11.81 & 13.40 & 14.98 & 16.56 & 18.14 \\
\hline$g_{2}=3.2$ & 2.5 & 1.37 & 2.32 & 3.26 & 4.21 & 5.15 & 6.10 & 7.04 & 7.99 & 8.93 & 9.88 & 10.82 \\
\hline \multicolumn{13}{|l|}{3} \\
\hline$g_{1}=8$ & 0.75 & 2.56 & 4.82 & 7.08 & 9.33 & 11.59 & 13.85 & 16.10 & 18.36 & 20.62 & 22.87 & 25.13 \\
\hline$g_{2}=2.67$ & 2.25 & 1.00 & 1.09 & 1.18 & 1.27 & 1.36 & 1.45 & 1.54 & 1.63 & 1.72 & 1.81 & 1.90 \\
\hline \multicolumn{13}{|l|}{4} \\
\hline$g_{1}=8$ & 1 & 2.70 & 5.24 & 7.78 & 10.32 & 12.86 & 15.41 & 17.95 & 20.49 & 23.03 & 25.57 & 28.11 \\
\hline$g_{2}=2$ & 2 & 1.00 & 1.09 & 1.18 & 1.27 & 1.36 & 1.45 & 1.54 & 1.63 & 1.72 & 1.81 & 1.90 \\
\hline \multicolumn{13}{|l|}{5} \\
\hline$g_{1}=8$ & 1.5 & 2.86 & 6.00 & 9.14 & 12.29 & 15.43 & 18.57 & 21.71 & 24.86 & 28.00 & 31.14 & 34.29 \\
\hline$g_{2}=0$ & 1.5 & 1.00 & 1.09 & 1.18 & 1.27 & 1.36 & 1.45 & 1.54 & 1.63 & 1.72 & 1.81 & 1.90 \\
\hline \multicolumn{13}{|l|}{6} \\
\hline$g_{1}=8$ & 2 & 2.94 & 6.44 & 9.94 & 13.44 & 16.94 & 20.44 & 23.94 & 27.44 & 30.94 & 34.44 & 37.94 \\
\hline$g_{2}=-4$ & 1 & 1.00 & 1.09 & 1.18 & 1.27 & 1.36 & 1.45 & 1.54 & 1.63 & 1.72 & 1.81 & 1.90 \\
\hline
\end{tabular}

TABle 3: VCC magnitude for PTSF at $V=100$.

\begin{tabular}{|c|c|c|c|c|c|c|c|c|c|c|c|c|}
\hline \multirow{2}{*}{ Grade (\%) } & \multirow{2}{*}{$\begin{array}{l}\text { Grade length } \\
\text { (miles) }\end{array}$} & \multicolumn{11}{|c|}{ Percent of heavy vehicle } \\
\hline & & $0 \%$ & $10 \%$ & $20 \%$ & $30 \%$ & $40 \%$ & $50 \%$ & $60 \%$ & $70 \%$ & $80 \%$ & $90 \%$ & $100 \%$ \\
\hline$g=4$ & 3 & 1.64 & 3.34 & 5.05 & 6.75 & 8.46 & 10.16 & 11.87 & 13.57 & 15.28 & 16.98 & 18.69 \\
\hline \multicolumn{13}{|l|}{1} \\
\hline$g_{1}=8$ & 1.00 & 1.00 & 1.00 & 1.00 & 1.00 & 1.00 & 1.00 & 1.00 & 1.00 & 1.00 & 1.00 & 1.00 \\
\hline$g_{2}=3.63$ & 1.03 & 1.00 & 1.08 & 1.16 & 1.24 & 1.32 & 1.40 & 1.48 & 1.56 & 1.64 & 1.72 & 1.80 \\
\hline \multicolumn{13}{|l|}{2} \\
\hline$g_{1}=8$ & 1.00 & 1.00 & 1.00 & 1.00 & 1.00 & 1.00 & 1.00 & 1.00 & 1.00 & 1.00 & 1.00 & 1.00 \\
\hline$g_{2}=3.2$ & 1.01 & 1.00 & 1.06 & 1.12 & 1.18 & 1.24 & 1.30 & 1.36 & 1.42 & 1.48 & 1.54 & 1.60 \\
\hline \multicolumn{13}{|l|}{3} \\
\hline$g_{1}=8$ & 1.00 & 1.00 & 1.00 & 1.00 & 1.00 & 1.00 & 1.00 & 1.00 & 1.00 & 1.00 & 1.00 & 1.00 \\
\hline$g_{2}=2.67$ & 1.00 & 1.00 & 1.01 & 1.02 & 1.03 & 1.04 & 1.05 & 1.06 & 1.07 & 1.08 & 1.09 & 1.10 \\
\hline \multicolumn{13}{|l|}{4} \\
\hline$g_{1}=8$ & 1.00 & 1.00 & 1.03 & 1.06 & 1.09 & 1.12 & 1.15 & 1.18 & 1.21 & 1.24 & 1.27 & 1.30 \\
\hline$g_{2}=2$ & 1.00 & 1.00 & 1.01 & 1.02 & 1.03 & 1.04 & 1.05 & 1.06 & 1.07 & 1.08 & 1.09 & 1.10 \\
\hline \multicolumn{13}{|l|}{5} \\
\hline$g_{1}=8$ & 1.00 & 1.00 & 1.11 & 1.22 & 1.33 & 1.44 & 1.55 & 1.66 & 1.77 & 1.88 & 1.99 & 2.10 \\
\hline$g_{2}=0$ & 1.00 & 1.00 & 1.01 & 1.02 & 1.03 & 1.04 & 1.05 & 1.06 & 1.07 & 1.08 & 1.09 & 1.10 \\
\hline \multicolumn{13}{|l|}{6} \\
\hline$g_{1}=8$ & 1.01 & 1.00 & 1.19 & 1.38 & 1.57 & 1.76 & 1.95 & 2.14 & 2.33 & 2.52 & 2.71 & 2.90 \\
\hline$g_{2}=-4$ & 1.00 & 1.00 & 1.01 & 1.02 & 1.03 & 1.04 & 1.05 & 1.06 & 1.07 & 1.08 & 1.09 & 1.10 \\
\hline
\end{tabular}


TABLE 4: VCC magnitude for ATS at $V=900$.

\begin{tabular}{|c|c|c|c|c|c|c|c|c|c|c|c|c|}
\hline \multirow{2}{*}{ Grade (\%) } & \multirow{2}{*}{$\begin{array}{l}\text { Grade length } \\
\quad \text { (miles) }\end{array}$} & \multicolumn{11}{|c|}{ Percent of heavy vehicle } \\
\hline & & $0 \%$ & $10 \%$ & $20 \%$ & $30 \%$ & $40 \%$ & $50 \%$ & $60 \%$ & $70 \%$ & $80 \%$ & $90 \%$ & $100 \%$ \\
\hline$g=4$ & 3 & 1.02 & 1.63 & 2.24 & 2.86 & 3.47 & 4.08 & 4.69 & 5.31 & 5.92 & 6.53 & 7.14 \\
\hline \multicolumn{13}{|l|}{1} \\
\hline$g_{1}=8$ & 1.00 & 1.00 & 1.34 & 1.68 & 2.02 & 2.36 & 2.70 & 3.04 & 3.38 & 3.72 & 4.06 & 4.40 \\
\hline$g_{2}=3.63$ & 1.03 & 1.03 & 1.64 & 2.25 & 2.86 & 3.46 & 4.07 & 4.68 & 5.29 & 5.90 & 6.51 & 7.11 \\
\hline \multicolumn{13}{|l|}{2} \\
\hline$g_{1}=8$ & 1.00 & 1.00 & 1.68 & 2.36 & 3.04 & 3.72 & 4.40 & 5.08 & 5.76 & 6.44 & 7.12 & 7.80 \\
\hline$g_{2}=3.2$ & 1.01 & 1.01 & 1.28 & 1.56 & 1.83 & 2.10 & 2.37 & 2.65 & 2.92 & 3.19 & 3.46 & 3.74 \\
\hline \multicolumn{13}{|l|}{3} \\
\hline$g_{1}=8$ & 1.00 & 1.00 & 1.92 & 2.84 & 3.76 & 4.68 & 5.60 & 6.52 & 7.44 & 8.36 & 9.28 & 10.20 \\
\hline$g_{2}=2.67$ & 1.00 & 1.00 & 1.00 & 1.00 & 1.00 & 1.00 & 1.00 & 1.00 & 1.00 & 1.00 & 1.00 & 1.00 \\
\hline \multicolumn{13}{|l|}{4} \\
\hline$g_{1}=8$ & 1.00 & 1.00 & 1.92 & 2.84 & 3.76 & 4.68 & 5.60 & 6.52 & 7.44 & 8.36 & 9.28 & 10.20 \\
\hline$g_{2}=2$ & 1.00 & 1.00 & 1.00 & 1.00 & 1.00 & 1.00 & 1.00 & 1.00 & 1.00 & 1.00 & 1.00 & 1.00 \\
\hline \multicolumn{13}{|l|}{5} \\
\hline$g_{1}=8$ & 1.00 & 1.00 & 2.07 & 3.14 & 4.21 & 5.28 & 6.35 & 7.42 & 8.49 & 9.56 & 10.63 & 11.70 \\
\hline$g_{2}=0$ & 1.00 & 1.00 & 1.00 & 1.00 & 1.00 & 1.00 & 1.00 & 1.00 & 1.00 & 1.00 & 1.00 & 1.00 \\
\hline \multicolumn{13}{|l|}{6} \\
\hline$g_{1}=8$ & 1.01 & 1.01 & 2.18 & 3.35 & 4.53 & 5.70 & 6.87 & 8.04 & 9.21 & 10.38 & 11.56 & 12.73 \\
\hline$g_{2}=-4$ & 1.00 & 1.00 & 1.00 & 1.00 & 1.00 & 1.00 & 1.00 & 1.00 & 1.00 & 1.00 & 1.00 & 1.00 \\
\hline
\end{tabular}

TABle 5: VCC magnitude for PTSF at $V=900$.

\begin{tabular}{|c|c|c|c|c|c|c|c|c|c|c|c|c|}
\hline \multirow{2}{*}{ Grade (\%) } & \multirow{2}{*}{$\begin{array}{l}\text { Grade length } \\
\text { (miles) }\end{array}$} & \multicolumn{11}{|c|}{ Percent of heavy vehicle } \\
\hline & & $0 \%$ & $10 \%$ & $20 \%$ & $30 \%$ & $40 \%$ & $50 \%$ & $60 \%$ & $70 \%$ & $80 \%$ & $90 \%$ & $100 \%$ \\
\hline$g=4$ & 3 & 1.02 & 1.63 & 2.24 & 2.86 & 3.47 & 4.08 & 4.69 & 5.31 & 5.92 & 6.53 & 7.14 \\
\hline \multicolumn{13}{|l|}{1} \\
\hline$g_{1}=8$ & 1.00 & 1.00 & 1.00 & 1.00 & 1.00 & 1.00 & 1.00 & 1.00 & 1.00 & 1.00 & 1.00 & 1.00 \\
\hline$g_{2}=3.63$ & 1.03 & 1.00 & 1.02 & 1.04 & 1.06 & 1.08 & 1.10 & 1.12 & 1.14 & 1.16 & 1.18 & 1.20 \\
\hline \multicolumn{13}{|l|}{2} \\
\hline$g_{1}=8$ & 1.00 & 1.00 & 1.00 & 1.00 & 1.00 & 1.00 & 1.00 & 1.00 & 1.00 & 1.00 & 1.00 & 1.00 \\
\hline$g_{2}=3.2$ & 1.01 & 1.00 & 1.00 & 1.00 & 1.00 & 1.00 & 1.00 & 1.00 & 1.00 & 1.00 & 1.00 & 1.00 \\
\hline \multicolumn{13}{|l|}{3} \\
\hline$g_{1}=8$ & 1.00 & 1.00 & 1.00 & 1.00 & 1.00 & 1.00 & 1.00 & 1.00 & 1.00 & 1.00 & 1.00 & 1.00 \\
\hline$g_{2}=2.67$ & 1.00 & 1.00 & 1.00 & 1.00 & 1.00 & 1.00 & 1.00 & 1.00 & 1.00 & 1.00 & 1.00 & 1.00 \\
\hline \multicolumn{13}{|l|}{4} \\
\hline$g_{1}=8$ & 1.00 & 1.00 & 1.04 & 1.08 & 1.12 & 1.16 & 1.20 & 1.24 & 1.28 & 1.32 & 1.36 & 1.40 \\
\hline$g_{2}=2$ & 1.00 & 1.00 & 1.00 & 1.00 & 1.00 & 1.00 & 1.00 & 1.00 & 1.00 & 1.00 & 1.00 & 1.00 \\
\hline \multicolumn{13}{|l|}{5} \\
\hline$g_{1}=8$ & 1.00 & 1.00 & 1.10 & 1.20 & 1.30 & 1.40 & 1.50 & 1.60 & 1.70 & 1.80 & 1.90 & 2.00 \\
\hline$g_{2}=0$ & 1.00 & 1.00 & 1.00 & 1.00 & 1.00 & 1.00 & 1.00 & 1.00 & 1.00 & 1.00 & 1.00 & 1.00 \\
\hline \multicolumn{13}{|l|}{6} \\
\hline$g_{1}=8$ & 1.01 & 1.00 & 1.13 & 1.26 & 1.39 & 1.52 & 1.65 & 1.78 & 1.91 & 2.04 & 2.17 & 2.30 \\
\hline$g_{2}=-4$ & 1.00 & 1.00 & 1.00 & 1.00 & 1.00 & 1.00 & 1.00 & 1.00 & 1.00 & 1.00 & 1.00 & 1.00 \\
\hline
\end{tabular}


Four examples are shown in Tables 2-5. In these tables, VCC magnitude is compared for a single grade and six substitute cases. The italic data indicate the worse condition of substitute cases than single grade. It is possible that a special configuration be preferable; note the change in $P_{T}$ could alter the result.

As shown in Tables 2 and 3, substituting alternative (2) is more effective in PTSF. While only the first case has better traffic operation for ATS, three first cases for PTSF show better results.

Tables 4 and 5 also show the same results but the condition for alternative (2) gets worse quicker.

Taking into account the limit of capacity of 1700 (pcu/h) and the assumption of PHF $=1$, VCC cannot exceed 17 and 1.9 for $V=100$ (veh/h) and $V=900$ (veh/h), respectively.

\section{Algorithm: Determining Optimum FG in Profile View}

As said earlier, the main objective of this study is to develop a procedure to optimize the FG in profile view. Based on aforementioned findings, the following algorithm is introduced.

(1) Determine the compulsory points in profile view (such as the entrance of tunnels and bridges).

(2) Determine the allowable tolerance in initial FG grades (based on parameters such as geotechnical considerations for maximum height of excavations or embankments).

(3) Determine if any tangent can be replaced by two tangents based on traffic operation considerations.

(4) Determine if any of the tangents which resulted in step (3) can be broken into two new ones based on the same manner.

(5) Determine if any two adjacent tangents could be combined to a single one that has a better traffic operation.

(6) Repeat steps (4) and (5) until the best FG line is achieved.

This algorithm can be used in design level of new constructed roads and even in rehabilitation projects. It is assumed that this algorithm may prevent constructing climbing lanes in individual cases.

\section{Conclusions}

This study was carried out to evaluate the traffic performance on upgrades, subjected to some limitations. Only specific TWTLHs upgrades were analyzed in Classes I and II; also no recreational vehicles were assumed in traffic composition.

Based on the results of this study, volume level and traffic composition have a contributing effect on traffic operation in specific upgrades on TWTLHs. So it is essential that transportation planners and engineers predict and manage traffic demand on these facilities as exactly as possible.

The results show that applying traffic restrictions on heavy vehicles may be an appropriate decision in order to improve the performance of a highway, without encountering serious problems in transportation and funding public money on what may not be necessary at the time. However, in this case, such a decision should be justified, both economically and traffic operationally.

The proposed algorithm determines that replacing a straight specific upgrade with two different grades and vice versa could improve the traffic performance of a TWTLH in special cases. Results show that as traffic volume increases, a single grade is more effective while using two separated grades is more efficient for Class II TWTLHs where PTSF is the only measure of effectiveness.

\section{Conflict of Interests}

The authors declare that there is no conflict of interests regarding the publication of this paper.

\section{Acknowledgment}

This paper was supported by Sazeh Energy Sahel (SES) Consulting Engineers, Tehran, Iran.

\section{References}

[1] D. W. Harwood, A. D. May, I. B. Anderson, L. Leiman, and A. R. Archilla, Capacity and Quality of Service of Two-Lane Highways, Midwest Research Institute, Kansas City, Mo, USA, 1999.

[2] A. Al-Kaisy and Z. Freedman, "Empirical examination of passing lane operational benefits on rural two-lane highways," Procedia-Social and Behavioral Sciences, vol. 16, pp. 340-351, 2011.

[3] Transportation Research Board, Highway Capacity Manual 2010, vol. 1-4, 2010.

[4] C. T. Durbin, Traffic performance on two-lane, two-way highways: examination of new analytical approaches [M.S. thesis], Montana State University, Bozeman, Mont, USA, 2006.

[5] J. Twagirimana, Establishing and applying speed-flow relationships for traffic on rural two-lane two-way highways in the Western Cape [M.S. thesis], Stellenbosch University, 2013.

[6] C. O'Flaherty, Transport Planning and Traffic Engineering, Elsevier, 1997.

[7] I. Ghosh, S. Chandra, and A. Boora, "Operational performance measures for two-lane roads: an assessment of methodological alternatives," Procedia-Social and Behavioral Sciences, vol. 104, pp. 440-448, 2013.

[8] I. H. Hashim and T. A. Abdel-Wahed, "Effect of highway geometric characteristics on capacity loss," Journal of Transportation Systems Engineering and Information Technology, vol. 12, no. 5, pp. 65-75, 2012.

[9] J. Kim and L. Elefteriadou, "Estimation of capacity of two-lane two-way highways using simulation model," Journal of Transportation Engineering, vol. 136, no. 1, Article ID 005001QTE, pp. 61-66, 2010.

[10] T. Luttinen, "Traffic flow on two-lane highways: an overview," TL Research Report 1/2001, TL Consulting Engineers, Ltd., Lahti, Finland, 2001.

[11] P. Rozic, "Capacity of two-lane, two-way rural highways: thenew approach," Transportation Research Record, 1992.

[12] E. K. Morlok, Introduction to Transportation Engineering and Planning, McGraw-Hill, New York, NY, USA, 1978. 
[13] A. Al-Kaisy and C. Durbin, "Percent time-spent-following on two-lane highways: a critique and new proposed techniques," in Proceedings of the Transportation Research Board 85th Annual Meeting, pp. 22-26, January 2006.

[14] S. Chandra, "Capacity estimation procedure for two lane roads under mixed traffic conditions," Journal of the Indian Roads Congress, vol. 65, no. 1, pp. 139-170, 2004.

[15] N. J. Garber and A. A. Ehrhart, "Final report: the effect of speed, flow, and geometric characteristics on crash rates for different types of Virginia highways," Tech. Rep., Virginia Transportation Research Council, Charlottesville, Va, USA, 2000.

[16] V. T. Arasan and S. S. Arkatkar, "Derivation of capacity standards for intercity roads carrying heterogeneous traffic using computer simulation," Procedia-Social and Behavioral Sciences, vol. 16, pp. 218-229, 2011.

[17] M. Parker, "The effect of heavy goods vehicles and following behaviour on capacity at motorway roadwork sites," Traffic Engineering \& Control, vol. 37, pp. 524-531, 1996.

[18] J. C. Oppenlander, Variables Influencing Spot-Speed Characteristics, vol. 89 of Highway Research Board Special Report, National Research Council, Highway Research Board, 1966.

[19] S. Yagar and M. van Aerde, "Geometric and environmental effects on speeds of 2-lane highways," Transportation Research Part A: General, vol. 17, no. 4, pp. 315-325, 1983.

[20] R. Troutbeck, "Analysis of free speeds," in Proceedings of the Australian Road Research Board Conference, Perth, Australia, 1976.

[21] H. Leong, "The distribution and trend of free speeds on two lane two way rural highways in New South Wales," in Proceedings of the 4th Australian Road Research Board Conference (ARRB '68), Melbourne, Australia, 1968

[22] T. F. Golob, W. W. Recker, and V. M. Alvarez, "Freeway safety as a function of traffic flow," Accident Analysis and Prevention, vol. 36, no. 6, pp. 933-946, 2004.

[23] R. P. Roess, Level of Service Concepts: Development, Philosophies, and Implications, Transportation Research Board, 1984.

[24] G. Book, A Policy on Geometric Design of Highways and Streets, AASHTO, 5th edition, 2004.

[25] A. Arun, S. Velmurugan, and M. Errampalli, "Methodological framework towards roadway capacity estimation for Indian multi-lane highways," Procedia-Social and Behavioral Sciences, vol. 104, pp. 477-486, 2013. 

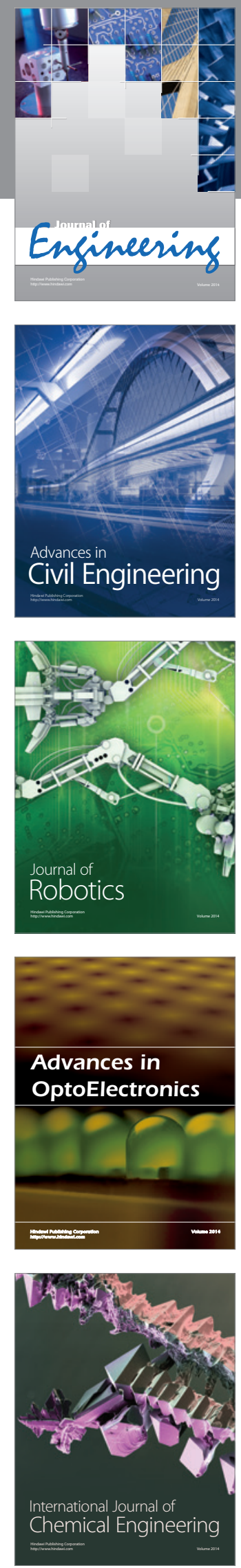

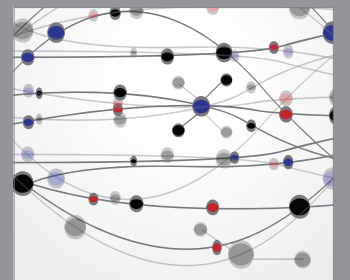

The Scientific World Journal
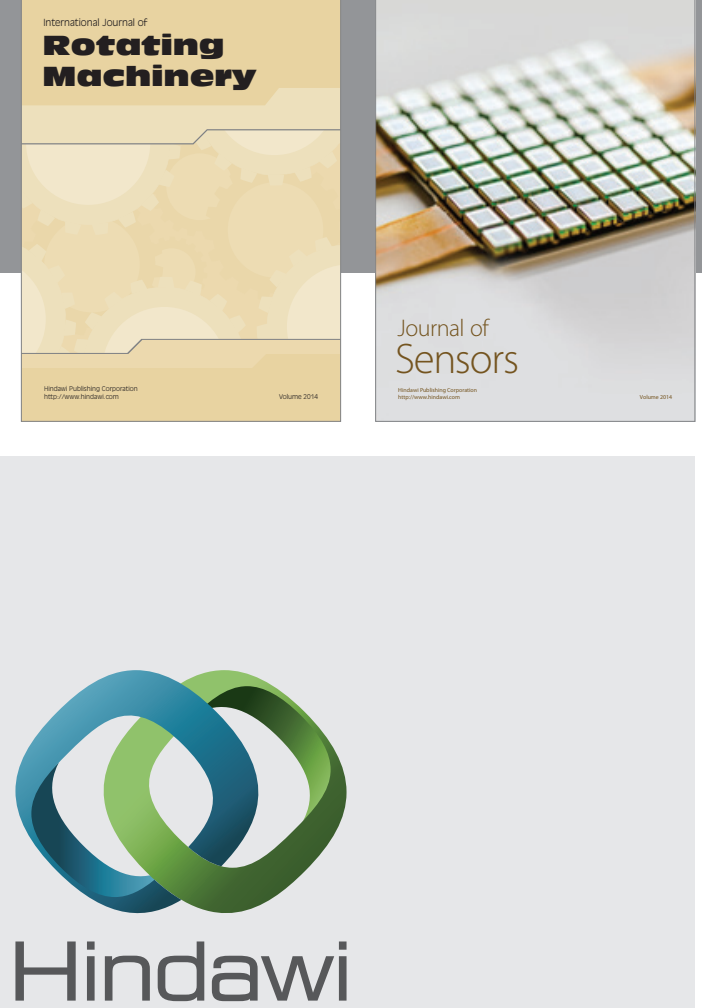

Submit your manuscripts at http://www.hindawi.com
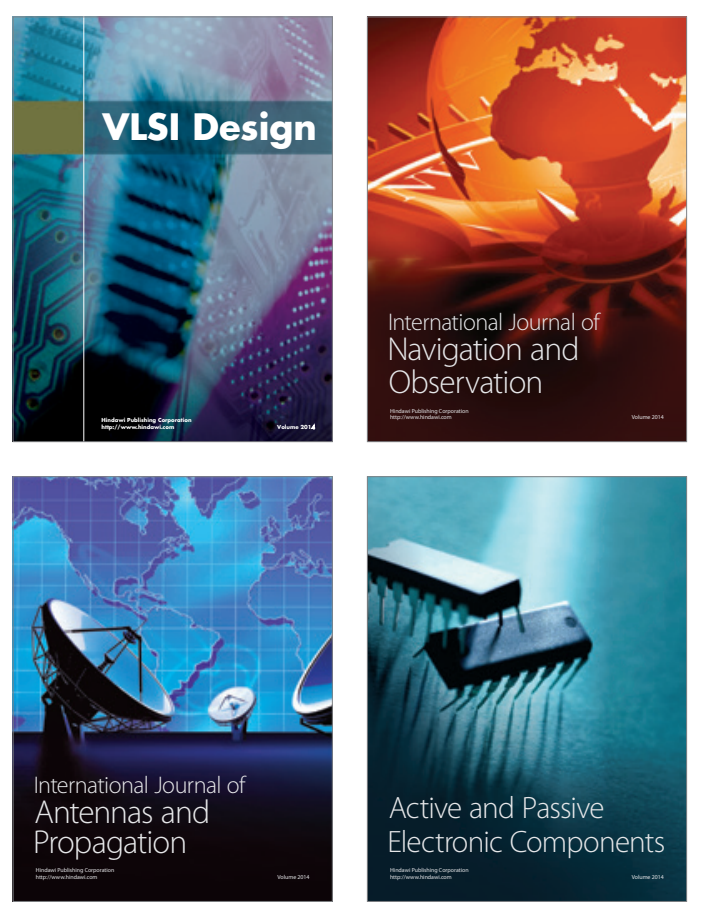
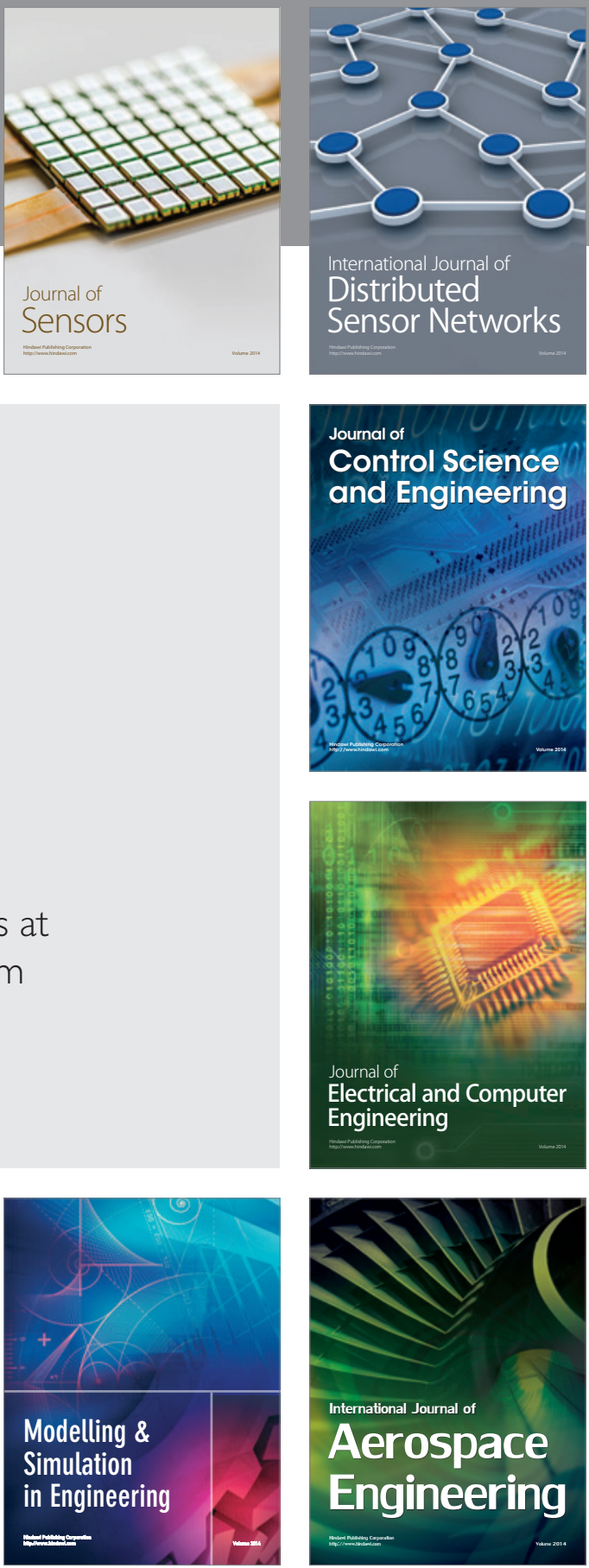

Journal of

Control Science

and Engineering
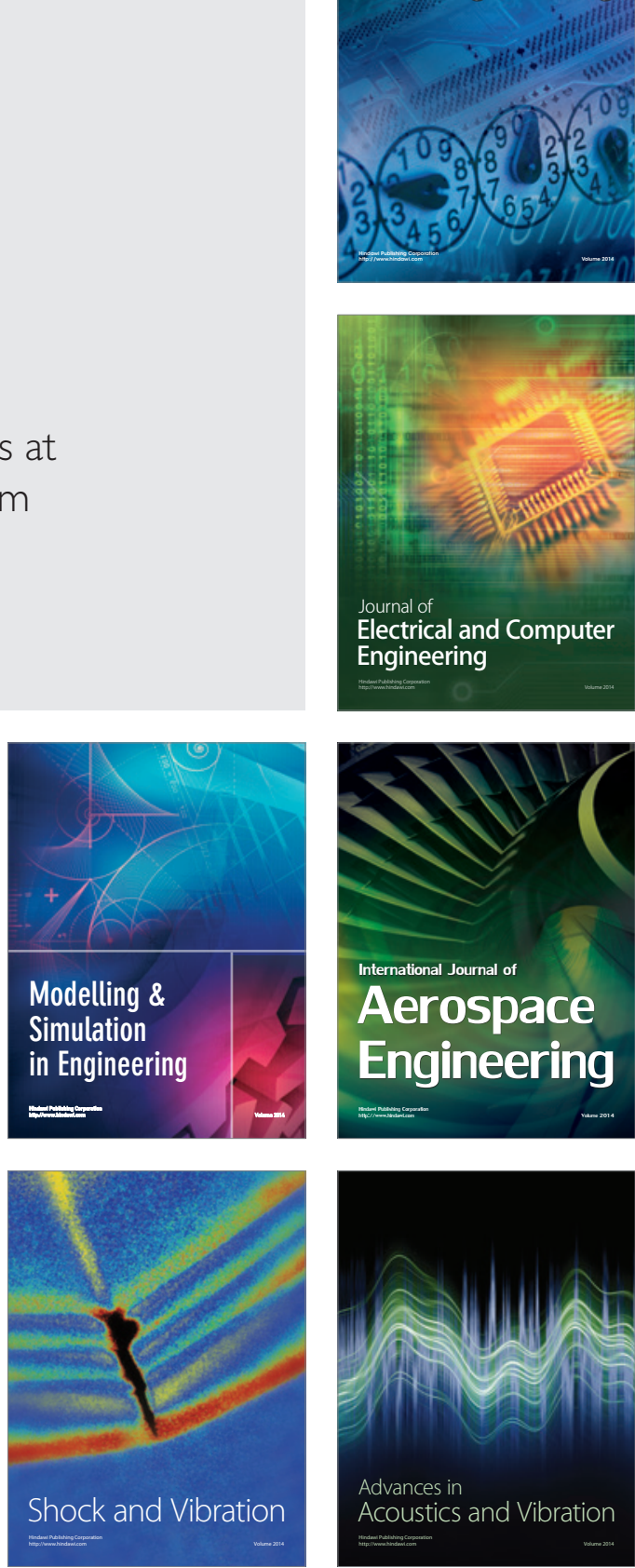